\title{
ANALYTICAL SOLUTION OF A 2D TRANSIENT HEAT CONDUCTION PROBLEM USING GREEN'S FUNCTIONS
}

\author{
J. R. F. Oliveira, \\ J. A. dos Santos Jr., \\ J. G. do Nascimento, \\ S. S. Ribeiro, \\ G. C. Oliveira, \\ G. R. Costa, \\ and G. Guimarães \\ Universidade Federal de Uberlandia \\ Faculdade de Engenharia Mecânica \\ Experiment and Modelling Heat TransferLaboratory \\ João Naves de Ávila, 2121, Uberlândia-MG, Brasil. \\ jose.ricardo@ufu.br \\ aguiarsjunior@gmail.com \\ jeffersongomes@ufu.br \\ sidney.ribeiros@hotmail.com \\ gabriela_costadeoliveira@hotmail.com \\ guilherme_r.c@hotmail.com \\ gguima@ufu.br \\ Received: May 23, 2019 \\ Revised: June 03, 2019 \\ Accepted: July 28, 2020
}

\section{ABSTRACT \\ Through the present work the authors determined the analytical} solution of a transient two-dimensional heat conduction problem using Green's Functions (GF). This method is very useful for solving cases where heat conduction is transient and whose boundary conditions vary with time. Boundary conditions of the problem in question, with rectangular geometry, are of the prescribed temperature type prescribed flow in the direction $\mathrm{x}$ and prescribed flow - prescribed flow in the direction $y$, implying in the corresponding GF given by $\mathrm{G}_{\mathrm{X} 21 \mathrm{Y} 22}$. The initial temperature of the space domain is assumed to be different from the prescribed temperature occurring at one of the boundaries along $\mathrm{x}$. The temperature field solution of the two-dimensional problem was determined. The intrinsic verification of this solution was made by comparing the solution of a 1D problem. This was to consider the incident heat fluxes at $y=0$ and $y=2 b$ tending to zero, thus making the problem one-dimensional, with corresponding GF given by GX21. When comparing the results obtained in both cases, for a time of $\mathrm{t}=1 \mathrm{~s}$, it was seen that the temperature field of both was very similar, which validates the solution obtained for the $2 \mathrm{D}$ problem.

Keywords: heat conduction; green's functions; intrinsic verification; prescribed temperature; prescribed flow

\section{NOMENCLATURE}

b flat plate dimension, $\mathrm{m}$

$\mathrm{f}_{\mathrm{i}} \quad$ initial condition

$\mathrm{g}$ heat generation, $\mathrm{Wm}^{-3}$

$\mathrm{k}$ thermal conductivity, $\mathrm{Wm}^{-1} \mathrm{~K}^{-1}$

$\mathrm{r}$ space domain

$\mathrm{S}_{\mathrm{i}} \quad$ surface

$\mathrm{T}$ temperature, ${ }^{\circ} \mathrm{C}$ or $\mathrm{K}$

$\mathrm{t}, \tau \quad$ time, $\mathrm{s}$

$\mathrm{x}, \mathrm{y}, \mathrm{z} \quad$ Cartesian axes

\section{Greek symbols}

$\begin{array}{ll}\alpha & \text { thermal diffusivity, } \mathrm{m}^{2} \mathrm{~s}^{-1} \\ \beta_{\mathrm{m}} & \text { eigenvalue } \\ \delta & \text { impulse }\end{array}$

\section{INTRODUCTION}

According to Beck et al. (1992), Green's Functions (GF) are very powerful tools to obtain solutions of linear, transient or permanent problems of heat conduction. They can be applied to the solution of some convection problems and too many other phenomena that are described by the same type of equations. According to Fernandes (2009), an advantage in the use of integral solutions by this method is the possibility of constructing multidimensional solutions from the one-dimensional GF. The versions of the solution equation $2 \mathrm{D}$ and $3 \mathrm{D}$ are absolutely equivalent to the one-dimensional equation and the GF can be obtained from products of $1 \mathrm{D}$ solution in the various directions.

According to Özişik (1993), the physical meaning of GF $\mathrm{G}\left(\mathrm{r}, \mathrm{t} \mid \mathrm{r}^{\prime}, \tau\right)$ in transient problems is the representation of temperature at location $r$ at time $t$ due to a point source instantaneous unity, located at point $r$ ', releasing energy at time $\tau$. Similarly, Carslaw and Jaeger (1959) define GF as the temperature distribution caused by a pulse of local and instantaneous energy. It was emphasized in Fernandes (2009) the importance of the use of GF in problems where the boundary conditions vary with time. In this case, the solution is immediately discarded through the method of separating variables. 
A method for determining the solution temperature field of a multilayer heat conduction problem through an inverse problem was evaluated in Oliveira et al. (2014). The solution of the proposed problem - double layer heat conduction - was based on GF. A mathematical analysis, analytical solution, intrinsic verification using other solutions and comparison with a solution was proposed in Ribeiro et al. (2015) of a transient 1D transient thermal model based on GF, considering a solid moving at a constant velocity along a Cartesian coordinate. In Ribeiro et al. (2018), both the temperature field and the heat flux supplied to a part during a process with a moving heat source were investigated in a $3 \mathrm{D}$ case of heat conduction.

A method of transfer function identification (or impulse response) was presented in Fernandeset al. (2015) to solve inverse heat conduction problems. The technique is based on GF and on the equivalence between thermal and dynamic systems. Inverse heat conduction problems, $1 \mathrm{D}$ and 3D transients called $\mathrm{X} 22$ and X33Y33Z33, respectively, are selected to present the fundamentals of the proposed method. Transient case 1D is a classical heat conduction problem used to obtain thermophysical properties and the transient $3 \mathrm{D}$ problem studied describes a machining process.

The objective of this work is to use Green's Functions to solve analytically a transient twodimensional heat conduction problem. In addition, the intrinsic verification of the solution obtained will be performed.

\section{GRENN'S FUNCTIONS FUNDAMENTALS}

It's considered the non-homogeneous threedimensional heat conduction problem with heat generation in the region R, given by Eq. (1)to (3).

$$
\begin{gathered}
\nabla^{2} \mathrm{~T}(\mathrm{r}, \mathrm{t})+\frac{1}{\mathrm{k}} \mathrm{g}(\mathrm{r}, \mathrm{t})=\frac{1}{\alpha} \frac{\partial(\mathrm{r}, \mathrm{t})}{\partial \mathrm{t}} \mathrm{t}>0 \\
\mathrm{k}_{\mathrm{i}} \frac{\partial \mathrm{T}}{\partial \mathrm{n}_{\mathrm{i}}}+\mathrm{h}_{\mathrm{i}} \mathrm{T}=\mathrm{h}_{\mathrm{i}} \mathrm{T}_{\infty \mathrm{i}} \equiv \mathrm{f}_{\mathrm{i}}(\mathrm{r}, \mathrm{t}) \text { in } \mathrm{S}_{\mathrm{i}}, \mathrm{t}>0 \\
\mathrm{~T}(\mathrm{r}, \mathrm{t})=\mathrm{F}(\mathrm{r}) \quad \mathrm{t}=0, \text { in } \mathrm{R}
\end{gathered}
$$

Where $\partial / \partial \mathrm{n}_{\mathrm{i}}$ denotes the normal gradient of the boundary surfaces $S_{i}, i=1,2 \ldots N$, where $N$ is the number of contour surfaces of the problem; $k_{i}$ and $h_{i}$ are treated as coefficients that are considered constant. To solve the problem, we consider the auxiliary problem, in the same region $\mathrm{R}$ :

$$
\begin{aligned}
\nabla^{2} \mathrm{G}\left(\mathrm{r}, \mathrm{t} \mid \mathrm{r}^{\prime}, \tau\right)+ & \frac{1}{\mathrm{k}} \delta\left(\mathrm{r}-\mathrm{r}^{\prime}\right) \delta(\mathrm{t}-\tau)=\frac{1}{\alpha} \frac{\partial \mathrm{G}}{\partial \mathrm{t}} \\
& \text { in } \mathrm{R}, \mathrm{t}>\tau
\end{aligned}
$$

$$
k_{i} \frac{\partial G}{\partial \eta_{i}}+h_{i} G=0 \text { in surface } S_{i}, t>\tau
$$

Where $\delta\left(r-r^{\prime}\right)$ is the point heat source located at $r^{\prime}$ and $\delta(t-\tau)$ instantaneous heat supply that occurs spontaneously at time $t=\tau$. Let $\mathrm{G}\left(\mathrm{r}, \mathrm{t} \mid \mathrm{r}^{\prime}, \tau\right)$ be a Green's Function. It represents the temperature at point $r$, at time $t$ due to a point source of heat, located at point $r$ ', and release of energy spontaneously at time $t=\tau$. While $(r, t)$ can be interpreted as the effect, that is, the temperature of the medium at point $r$ at time $t,\left(r^{\prime}, \tau\right)$ represents an impulse, that is, an instantaneous generation source at point $r$, whose heat release occurs spontaneously at time $t$. For the case of the 3D, transient, non-homogeneous heat conduction problem given above, the solution for $T(r, t)$ is expressed in terms of a function of Green three-dimensional $\mathrm{G}\left(\mathrm{r}, \mathrm{t} \mid \mathrm{r}^{\prime}, \tau\right)$ as:

$$
\begin{aligned}
& \mathrm{T}(\mathrm{r}, \mathrm{t})= \\
& =\int_{\mathrm{R}} \mathrm{G}\left(\mathrm{r}, \mathrm{t} \mid \mathrm{r}^{\prime}, \mathrm{t}\right)_{\tau=0} \mathrm{~F}\left(\mathrm{r}^{\prime}\right) \mathrm{dv}^{\prime}+ \\
& +\frac{\alpha}{\mathrm{k}} \int_{\tau=0}^{\mathrm{t}} \int_{\mathrm{R}} \mathrm{G}\left(\mathrm{r}, \mathrm{t} \mid \mathrm{r}^{\prime}, \tau\right) \mathrm{g}\left(\mathrm{r}^{\prime}, \tau\right) \mathrm{dv^{ \prime } \mathrm { d } \tau +} \\
& +\alpha \int_{\tau=0}^{\mathrm{t}} \sum_{\mathrm{i}=1}^{\mathrm{N}} \int_{\mathrm{S}_{\mathrm{i}}} \mathrm{G}\left(\mathrm{r}, \mathrm{t} \mid \mathrm{r}^{\prime}, \tau\right)_{\mathrm{r}^{\prime}=\mathrm{r}_{\mathrm{i}}} \frac{\mathrm{f}_{\mathrm{i}}\left(\mathrm{r}^{\prime}, \tau\right)}{\mathrm{k}_{\mathrm{i}}} \mathrm{ds}_{\mathrm{i}}{ }^{\prime} \mathrm{d} \tau
\end{aligned}
$$

The first term of Eq. (6) signifies the contribution of the initial condition function $\mathrm{F}(\mathrm{r})$ to the temperature distribution, that is, the GF evaluated for $\tau=0$ is multiplied by $F(r)$ and integrated along the region $\mathrm{R}$. The second term of Eq. (6) refers to the contribution of the general term $(R, t)$ in the temperature distribution $\mathrm{T}(\mathrm{r}, \mathrm{t})$, that is, the GF multiplied by the integrated generation term in the region $\mathrm{R}$ and the time from $\tau=0$ to $t$. The third term of Eq. (6) brings the contribution of the nonhomogeneous term $f_{i}(r, t)$ of the boundary conditions in the temperature distribution, consisting of the function (T), which is integrated in the boundary surface and in the time from $\tau=0$ to $\mathrm{t}$.

\section{ANALYTICAL SOLUTION}

As can be seen in Fig. 1, the proposed problem $2 \mathrm{D}$ is of the type $\mathrm{X} 21 \mathrm{Y} 22$. It is worth noting that at $\mathrm{y}$ $=0$ and at $y=2 b$, there is a heat flux at $0 \leq x \leq b$, and at $\mathrm{b} \leq \mathrm{x} \leq 2 \mathrm{~b}$ there is thermal isolation. In this way, Eq. (7) represents GX21Y22.

Figure 2 shows the temperature field at $t=10 \mathrm{~s}$ and $\mathrm{t}=100 \mathrm{~s}$, respectively. Dimensions and thermophysical properties considered for this analysis were $\mathrm{x}=\mathrm{y}=100 \mathrm{~mm}, \mathrm{~b}=50 \mathrm{~mm}, \mathrm{k}=14.9 \mathrm{Wm}^{-1} \mathrm{~K}^{-1}$, $\alpha=3.95 \times 10^{-6} \mathrm{~m}^{2} \mathrm{~s}^{-1}, \mathrm{q} 0 "=10^{4} \mathrm{Wm}^{-2}, \mathrm{q} 2 "=2 \times 10^{4}$ $\mathrm{Wm}^{-2}, \mathrm{~T} 1=303.15 \mathrm{~K}$ and $\mathrm{T} 0=283.15 \mathrm{~K}$. 
$G_{X 21 Y 22}=\frac{1}{2 b^{2}} \times$

$\times \sum_{m=1}^{\infty} e^{\left[-\left(\frac{\beta_{m}}{2 b}\right)^{2} \alpha(t-\tau)\right]} \cos \left(\frac{\beta_{m} x}{2 b}\right) \cos \left(\frac{\beta_{m} x^{\prime}}{2 b}\right)+$

$+\frac{1}{b^{2}} \times$

$\times \sum_{m=1}^{\infty} e^{\left[-\left(\frac{m \pi}{2 b}\right)^{2} \alpha(t-\tau)\right]} \cos \left(\frac{m \pi y}{2 b}\right) \cos \left(\frac{m \pi y^{\prime}}{2 b}\right) \times$

$\times \sum_{m=1}^{\infty} e^{\left[-\left(\frac{\beta_{m}}{2 b}\right)^{2} \alpha(t-\tau)\right]} \cos \left(\frac{\beta_{m} x}{2 b}\right) \cos \left(\frac{\beta_{m} x^{\prime}}{2 b}\right)$

were

$$
\beta_{m}=\pi\left(m-\frac{1}{2}\right)
$$

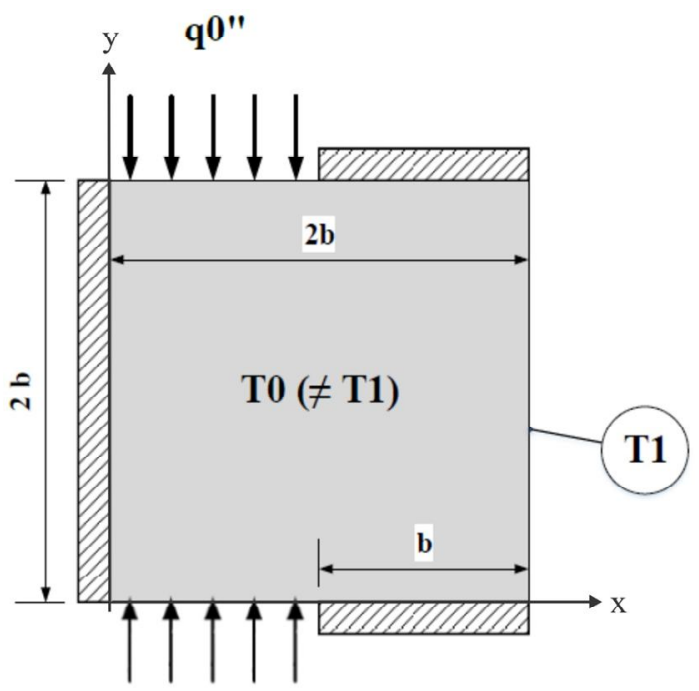

a2"

Figure 1. Proposed problem.

Initial and boundary conditions are described from Eq. (8) to Eq. (14).

$$
\begin{gathered}
\mathrm{T}(\mathrm{x}, \mathrm{y}, 0)=\mathrm{T}_{0} \\
-\left.\mathrm{k} \frac{\partial \mathrm{T}}{\partial \mathrm{x}}\right|_{\mathrm{x}=0}=0 \\
\left.\mathrm{~T}(\mathrm{x}, \mathrm{y}, \mathrm{t})\right|_{\mathrm{x}=2 \mathrm{~b}}=\mathrm{T}_{1}
\end{gathered}
$$

$$
\begin{aligned}
& -\left.\mathrm{k} \frac{\partial \mathrm{T}}{\partial \mathrm{y}}\right|_{\mathrm{y}=0}=\mathrm{q}_{2} " \quad \text { in } \quad 0 \leq \mathrm{x} \leq \mathrm{b} \\
& -\left.\mathrm{k} \frac{\partial \mathrm{T}}{\partial \mathrm{y}}\right|_{\mathrm{y}=0}=0 \quad \text { in } \quad \mathrm{b} \leq \mathrm{x} \leq 2 \mathrm{~b} \\
& -\left.\mathrm{k} \frac{\partial \mathrm{T}}{\partial \mathrm{y}}\right|_{\mathrm{y}=\mathrm{b}}=\mathrm{q}_{0} ” \quad \text { in } \quad 0 \leq \mathrm{x} \leq \mathrm{b} \\
& -\left.\mathrm{k} \frac{\partial \mathrm{T}}{\partial \mathrm{y}}\right|_{\mathrm{y}=\mathrm{b}}=0 \quad \text { in } \quad \mathrm{b} \leq \mathrm{x} \leq 2 \mathrm{~b}
\end{aligned}
$$

Using Eq. (5), solution temperature field will be given by Eq. (15).

$\mathrm{T}(\mathrm{x}, \mathrm{y}, \mathrm{t})=$

$=2 \mathrm{~T}_{0}\left\{\sum_{\mathrm{m}=1}^{\infty} \mathrm{e}^{\left[-\left(\frac{\beta_{\mathrm{m}}}{2 \mathrm{~b}}\right)^{2} \alpha \mathrm{t}\right]} \cos \left(\frac{\beta_{\mathrm{m}} \mathrm{X}}{2 \mathrm{~b}}\right) \frac{\operatorname{sen}\left(\beta_{\mathrm{m}}\right)}{\beta_{\mathrm{m}}}+\right.$

$+2 \sum_{m=1}^{\infty} \mathrm{e}^{\left[-\left(\frac{\mathrm{m} \pi}{2 \mathrm{~b}}\right)^{2} \alpha \mathrm{t}\right]} \cos \left(\frac{\mathrm{m} \pi \mathrm{y}}{2 \mathrm{~b}}\right) \frac{\operatorname{sen}(\mathrm{m} \pi)}{\mathrm{m} \pi} \times$

$\left.\times \sum_{\mathrm{m}=1}^{\infty} \mathrm{e}^{\left[-\left(\frac{\beta_{\mathrm{m}}}{2 \mathrm{~b}}\right)^{2} \alpha \mathrm{t}\right]} \cos \left(\frac{\beta_{\mathrm{m}} \mathrm{X}}{2 \mathrm{~b}}\right) \frac{\operatorname{sen}\left(\beta_{\mathrm{m}}\right)}{\beta_{\mathrm{m}}}\right\}+$

$+\frac{2 \mathrm{bT}_{1}}{\mathrm{k}} \sum_{\mathrm{m}=1}^{\infty} \cos \left(\frac{\beta_{\mathrm{m}} \mathrm{x}}{2 \mathrm{~b}}\right) \frac{\left\{1-\mathrm{e}^{\left[-\left(\frac{\beta_{\mathrm{m}}}{2 \mathrm{~b}}\right)^{2} \alpha \mathrm{t}\right]}\right\}}{\beta_{\mathrm{m}}}+$

$+\frac{2 \alpha}{b k}\left(q_{0}+q_{2}\right) \times$

$\times \int_{0}^{\mathrm{t}} \sum_{\mathrm{m}=1}^{\infty} \mathrm{e}^{\left[-\left(\frac{\mathrm{m} \pi}{2 \mathrm{~b}}\right)^{2} \alpha(\mathrm{t}-\tau)\right]} \cos \left(\frac{\mathrm{m} \pi \mathrm{y}}{2 \mathrm{~b}}\right) \times \mathbf{A} \times \mathrm{d} \tau$

where

$$
\mathbf{A}=\sum_{\mathrm{m}=1}^{\infty} \cos \left(\frac{\beta_{\mathrm{m}} \mathrm{x}}{2 \mathrm{~b}}\right) \frac{\operatorname{sen}\left(\frac{\beta_{\mathrm{m}}}{2}\right) \mathrm{e}^{\left[-\left(\frac{\beta_{\mathrm{m}}}{2 \mathrm{~b}}\right)^{2} \alpha(\mathrm{t}-\tau)\right]}}{\beta_{\mathrm{m}}}
$$

In order to validate this solution, intrinsic verification was performed, where the heat flux incident on the flat plate of Fig. 1 were reduced to the point where they tended to zero. Thus, the problem becomes one-dimensional in the x-direction, where GX21 is the GF for this case.

Figure 4 shows that the temperature fields of cases $1 \mathrm{D}$ and $2 \mathrm{D}$ are similar for the time evaluated. Figure 5 shows that there is a residual difference between the cases presented, for $t=1 \mathrm{~s}$. Since the 
order of magnitude of this residual value is very small, it can be said that the solution of the $2 \mathrm{D}$ case is validated.

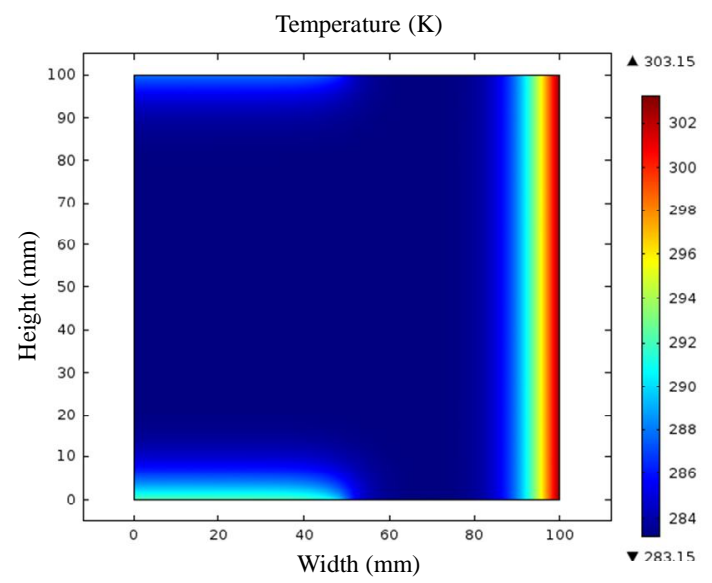

Figure 2. Temperature field $T(x, y, t)$ at $t=10 \mathrm{~s}$.

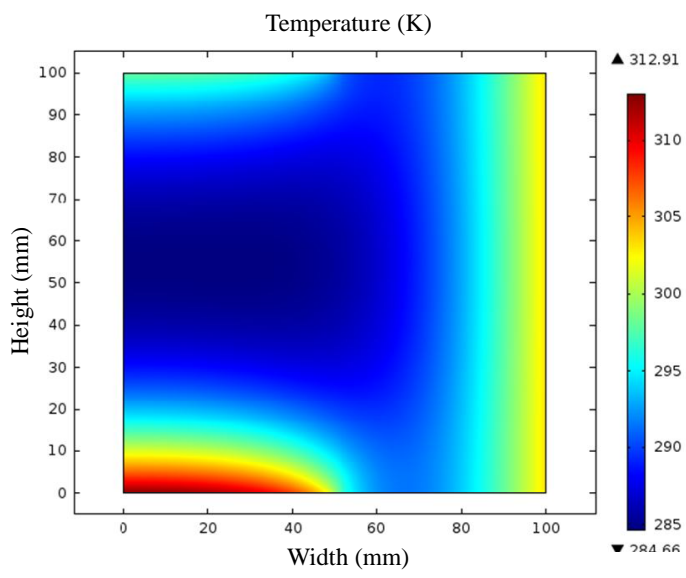

Figure 3. Temperature field $\mathrm{T}(\mathrm{x}, \mathrm{y}, \mathrm{t})$ at $\mathrm{t}=100 \mathrm{~s}$.

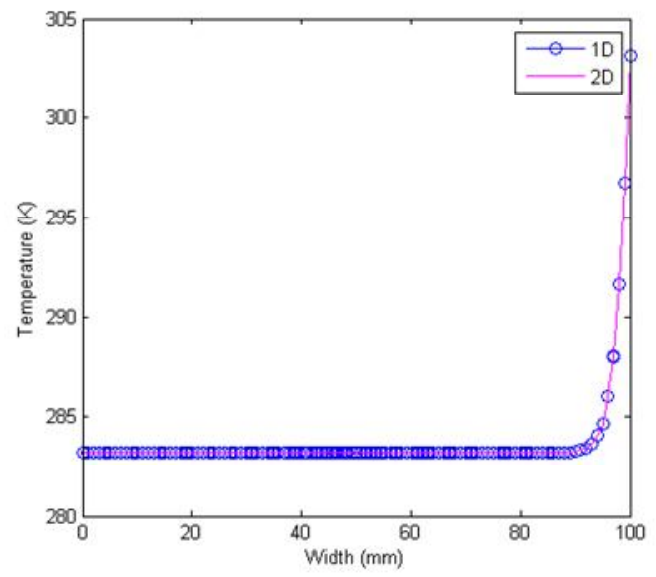

Figure 4. Temperature along the plate at $y=50 \mathrm{~mm}$ at $\mathrm{t}=1 \mathrm{~s}$.

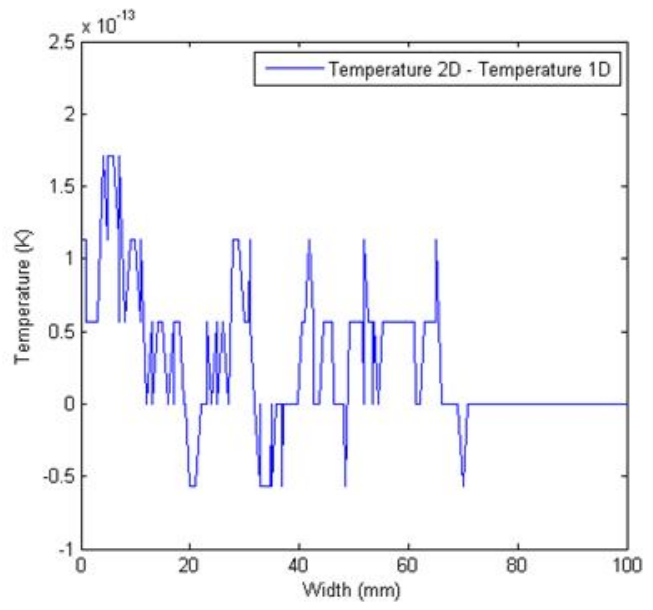

Figure 5. Residual temperature difference between cases $1 \mathrm{D}$ and $2 \mathrm{D}$.

\section{CONCLUSIONS}

A 2D problem was presented, whose corresponding Green's Function is given by GX21Y22. Given the initial and boundary conditions, is obtained the solution temperature field of the proposed problem, whose validation was performed by admitting the heat fluxes incident at $\mathrm{y}=0$ and $\mathrm{y}=$ $2 \mathrm{~b}$ tending to zero, which makes the proposed problem a problem $1 \mathrm{D}$, with corresponding GF given by GX21. Subsequently, temperature curves of both cases were evaluated for $y=50 \mathrm{~mm}$ and $\mathrm{t}=10 \mathrm{~s}$. It was observed that the determined temperature fields are the same for the evaluated time, validating the temperature field obtained for the $2 \mathrm{D}$ problem.

\section{ACKNOWLEDGEMENTS}

The authors thank CNPq, CAPES and FAPEMIG for the financial support granted during this work.

\section{REFERENCES}

Beck, J. V., Cole, K. D., and Haji-Sheikh, A., 1992, Heat Conduction Using Green's Functions, Hemisphere Publishing.

Carslaw, H. S., and Jaeger, J. C., 1959, Conduction of Heat in Solids, 2nd Edition, Clarend on Press, Oxford.

Fernandes, A. P., 2009, Funções de Green: soluções Analíticas Aplicadas e Problemas Inversos em Condução de Calor, Master Thesis, Universidade Federal de Uberlândia, Uberlândia-MG (in Portuguese).

Fernandes, A. P., Santos, M. B., and Guimarães, G., 2015, Analytical Transfer Function Method to Solve Inverse Heat Conduction Problems, Applied Mathematical Modelling, Vol. 39, pp. 6897-6914. 
Oliveira, G. C., Fernandes, A. P., and Guimarães, G., 2014, An Analytical Temperature Solution Analysis for a Multilayer Heat Conduction Problem, Thermal Engineering, Vol. 13, No. 2, pp. 89-95.

Özişik, M. N., 1993, Heat Conduction, 2nd Edition, John Wiley and Sons, New York.

Ribeiro, S. S., Guimarães, G., Fernandes, A., and Oliveira, G. C., 2015, Heat Conduction in Moving Solids Using Green's Function, Thermal Engineering, Vol. 14, No. 1, pp. 65-70.

Ribeiro, S. S., Oliveira, G. C., and Guimarães, G., 2018, An Inverse Problem using Green's Functions and TFBGF Method to Identificate a Moving Heat Source in 3D Heat Conduction, Thermal Engineering, Vol. 17, No. 2, pp. 87-91. 